\title{
Formation of Pedagogical Thinking of Future Teachers
}

\author{
VALENTYNA BOICHENKO ${ }^{1}$, LARISA YOVENKO ${ }^{2}$, TETYANA REMEKH ${ }^{3}$, OKSANA TSYHANOK ${ }^{4 *}$, \\ VITA KYRYCHENKO ${ }^{5}$, BOHDAN HUBA ${ }^{6}$ \\ ${ }^{1}$ Department of Pedagogy and Educational Management, PAVEL TYCHYNA UMAN STATE PEDAGOGICAL \\ UNIVERSITY, UKRAINE. \\ 2,4,5 Department of Ukrainian Literature, Ukrainian Studies and Teaching Methods, PAVEL TYCHYNA UMAN \\ STATE PEDAGOGICAL UNIVERSITY, UKRAINE, *E-mail: 585-585@ukr.net. \\ ${ }^{3}$ Department of Social Science Education, INSTITUTE OF PEDAGOGY OF THE NATIONAL ACADEMY OF \\ EDUCATIONAL SCIENCES OF UKRAINE, UKRAINE. \\ ${ }^{6}$ Department of Educational and Sociocultural Management, BOHDAN KHMELNYTSKY NATIONAL UNIVERSITY, \\ UKRAINE.
}

\begin{abstract}
The training of professional teachers is dictated by the fundamental changes taking place in education. In the new social and pedagogical conditions, a professional teacher is required. Unlike a specialist teacher, a professional teacher, firstly, is a subject of the pedagogical activity, and not a bearer of a set of scientific knowledge and methods of its transmission; secondly, it is focused on the development of human abilities, and not only on the transmission of knowledge, abilities and skills; thirdly, he can practically work with educational processes, to build developing educational situations, and not just to pose and solve didactic problems. The analysis of literary sources allowed the authors to achieve the goal of the article: to develop theoretical and methodological tools for the significant formation of pedagogical thinking of future teachers, namely, to offer and test a model for the formation of pedagogical thinking of future teachers. The approbation showed an increase in all indicators that were assessed, as well as an increase in additional indicators: student attendance and their involvement in the educational process, which was manifested in an increase in the number of students who came to consultations, an increase in the number of requests from students to study additional literature on the topic, for additional research work, etc. Thus, the development of pedagogical thinking becomes both a process and a result of teaching a future teacher.
\end{abstract}

Keywords: future teacher, pedagogical thinking, student.

JEL Classification: D91; D79; D01 


\section{Introduction.}

Fundamental education, reflecting the current state of science and technology, presupposes the ability of future specialists not only to perceive someone else's experience actively but also to intellectual creativity. It is precisely this type of education that modern universities are aimed at, actively combining educational and research processes (Salminen \& Annevirta, 2016). The need for a student - a future teacher - to master pedagogical skills is due to the nature of the professional activity of a modern teacher. Practice shows that the very creative nature of pedagogical activity requires the teacher to be able to explore the educational process, to approach the issue of its organization from a scientific standpoint. An essential condition for the formation of students' pedagogical skills is the motivation of pedagogical activity: stimulating interest, justifying the need for research work in the requirements of a modern school, the prestige of possessing the system of these skills, and the importance for professional growth.

The training of professional teachers is dictated by the fundamental changes taking place in education (Demikhova et al., 2016; Prokopenko et al., 2020; Tkachenko et al., 2019). New values have appeared in society: self-development, self-education and self-projection of the individual, which have become the basis of a new paradigm in pedagogy - personality-oriented education. The space of pedagogical activity has significantly expanded. The traditional system of pedagogical education, focused on training subject specialists, is no longer able to satisfy the demands of modern pedagogical practice.

The task of training professionals for the main spheres of human activity in the modern sociocultural situation has acquired particular relevance. The activity of a professional is contrasted with the activity of a performer and a narrow specialist (Trigwell \& Shale, 2004). A professional as a subject of labour, in contrast to a performer, sets goals for the activity, determines the ways and means of achieving them, and bears responsibility for the consequences of its implementation. Unlike a specialist, a professional owns an activity as a whole, maintains its objectivity in a variety of practical situations, is capable of building activity, changing it and developing it.

In the new social and pedagogical conditions, a professional teacher is required. Unlike a specialist teacher, a professional teacher, firstly, is a subject of the pedagogical activity, and not a bearer of a set of scientific knowledge and methods of its transmission; secondly, it is focused on the development of human abilities, and not only on the transmission of knowledge, abilities and skills; thirdly, he is able to practically work with educational processes, to build developing educational situations, and not just to pose and solve didactic problems.

\section{Statement of the problem and purpose of the study.}

Observations of students' mental activity in Pavel Tychyna Uman State Pedagogical University (PTUSPU) and the Institute of Pedagogy of the National Academy of Educational Sciences of Ukraine (IP NAESU) during classes during their pedagogical practice, while performing scientific work revealed several problems and shortcomings related to the low level of mental culture in general and pedagogical thinking (Fig. 1).

The definition of these shortcomings is aimed at identifying and eliminating gaps in the preparation of future teachers for mental activity, namely: the formation of his pedagogical thinking as one of the leading professional competencies in higher education, even though professional competence is formed and changed during all human life. Thus, the article aims to develop theoretical and methodological tools for the effective formation of pedagogical thinking of future teachers. 
Figure 1. The results of the observation of students' mental activity (2015-2016)

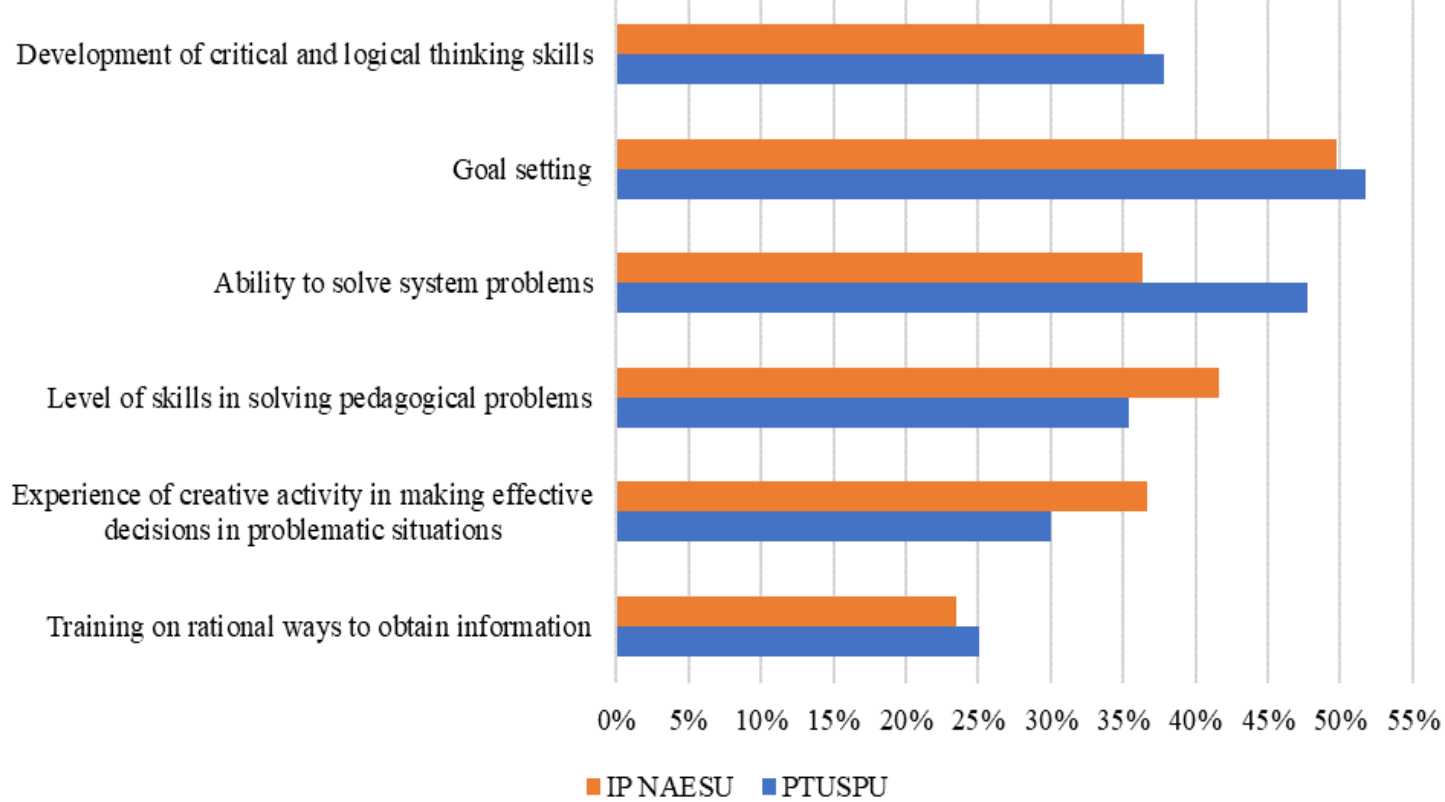

Source: Research findings

\section{The essence of pedagogical thinking.}

Pedagogical thinking is defined as a set of cognitive processes aimed at solving professional problems of human development management, which are infinitely diverse and characterized by specificity depending on age, experience, social status of people (Mylläri et al., 2011; O'brien, 2012). That is, pedagogical thinking is an activity of understanding pedagogical phenomena and is an active process of reflecting the objective world in the form of concepts, judgments, inferences. Pedagogical thinking gives a particular understanding of the essence of the educational process, the goals of pedagogical activities, ways and means of achieving them, a specific understanding of the individual as a subject of education. Thinking is possible in an unconscious, "automatic" state, at the level of skill, without awareness of the process of solving some simple and standard pedagogical problems. Pedagogical thinking as an ideal form of reflection of educational processes has no meaning of its own. Its content is a variety of pedagogical activities, analysis, synthesis, comparison, classification, extrapolation of its components (Vozniak, 2019; Milner-Bolotin, 2020). Scientific, pedagogical thinking cannot exist only in an ideal form. "Matter" of pedagogical thinking - the conceptual and terminological basis of the science of education. The essence of thinking is to correlate the elements of the pedagogical process - the purpose, content of education, teaching and learning activities. The functions of pedagogical thinking are the solution of various pedagogical problems, problems and solutions to complex pedagogical situations. Accordingly, the subject of the action of thinking is a pedagogical situation, event, action.

The most critical elements of pedagogical thinking are found in different situations, which are invariant, as well as pedagogical thinking, because it is aimed at understanding the interacting system, analyzing a set of conditions, pedagogical situations and solving pedagogical problems (Colton et al., 1989; Boichenko, 2015). Pedagogical thinking is extra historical: in ancient times, teachers performed the same mental operations as our contemporaries.

Consider the functions of pedagogical thinking at different stages of solving the pedagogical problem in the field of education (Fig. 2). 
Figure 2. Functions of pedagogical thinking at different stages of solving a pedagogical problem

\begin{tabular}{|c|c|}
\hline $\begin{array}{c}\text { Design stage } \\
\text { Implementation } \\
\text { stage } \\
\text { and development of ways of its decision }\end{array}$ \\
\hline $\begin{array}{c}\text { obtaining operational information about the success of } \\
\text { students, the organization of activities to solve the } \\
\text { educational task and its operational regulation }\end{array}$ \\
\hline Evaluation stage \\
the achieved results are analysed and the directions of \\
further work are determined
\end{tabular}

Source: Research findings

The analysis of scientific sources allowed to define such most general features of pedagogical thinking (Fig. 3).

Figure 3. General features of pedagogical thinking

\begin{tabular}{|l} 
the need to operate with concepts, inferences not only of science, a professional \\
practice, but also morality (in the field of morality special logic - it is based not \\
on the category of truth, but on such "modal" categories as "possible", \\
"impossible", "Good", "bad", "allowed", "acceptable", etc.);
\end{tabular}

Source: Research findings

The generalized ability to think pedagogically presupposes that the teacher has analytical, prognostic, projective, and also reflective skills (Fig. 4).

1. Analytical skills include the ability to analyze pedagogical phenomena.

2. Prognostic skills are associated with the management of the educational process and involve the focus on a clear imagination in the minds of the teacher who is the subject of management, the goals of its activities in the form of the expected result. Pedagogical forecasting is based on reliable knowledge of the essence and logic of the pedagogical process, the laws of age and individual development of students.

3. Projective skills are implemented in the form of project development of the educational process.

4. Reflexive skills take place in the implementation of the teacher's control activities aimed at themselves and involve the use of such varieties as control. 
Figure 4. Necessary skills of the teacher as a guarantee of pedagogical thinking

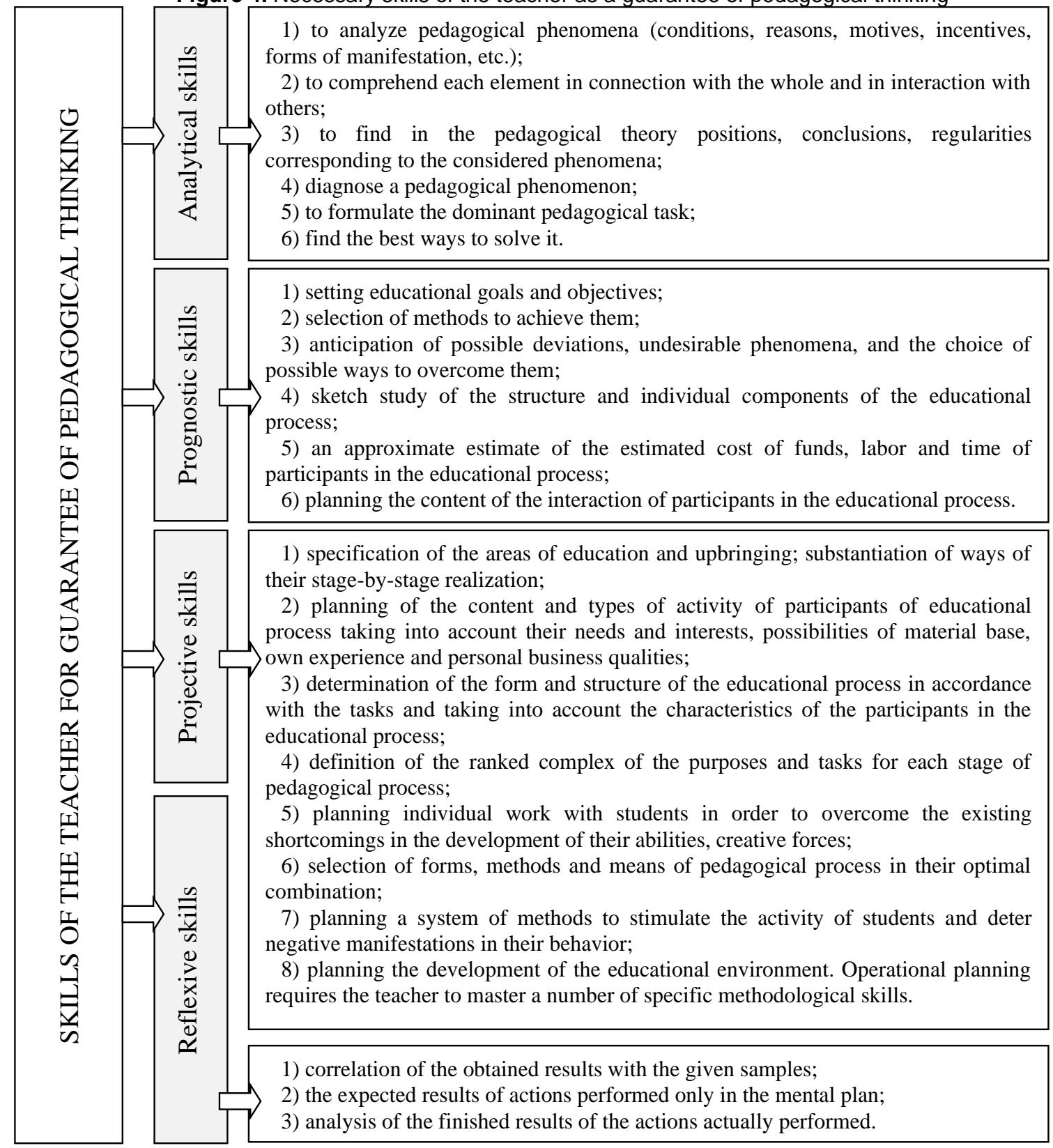

Source: Research findings

The last type of control deserves special attention as the most often applied in the activity of the teacher. For its effective implementation, the teacher must be able to reflect, which allows you to analyze their judgments, actions objectively, and ultimately in terms of their compliance with the goals and conditions of their implementation. We understand reflection as a specific form of theoretical activity aimed at understanding and analyzing their own actions.

The teacher needs to establish to what extent the obtained results (positive and negative) are a consequence of his activity. Hence the need for analysis of their own actions, during which are determined:

- the correctness of goal setting, their transformation into specific tasks;

- the adequacy of the set of dominant and subordinate tasks to be solved, the necessary conditions;

- compliance of the content of students' activities with the task;

- the effectiveness of the methods used, techniques and means of pedagogical activity; 
- correspondence of organizational forms - to age features of pupils, a level of their development, the maintenance of material, etc .;

- the reasons for successes and failures, mistakes, and difficulties in the course of realization of the set tasks of training and education;

- experience of its activity in its integrity and compliance with the criteria developed in science.

Thus, the teacher's thinking should be characterized by independence of judgment, originality, systematicity, accuracy, depth, critical work, dexterity, intelligence, ingenuity, intuition, prudence. The teacher's thinking is manifested in the solution of non-standard tasks, in the construction of new methods of pedagogical influence, in the design of pedagogical systems.

\section{Tools for the formation of pedagogical thinking of future teachers.}

The preliminary theoretical analysis allows us to define pedagogical thinking as an integrative personal education, which is manifested in the ability to consciously use pedagogical ideas, knowledge and skills in specific situations of professional activity, to see in certain phenomena of professional activity pedagogical essence and choose adequate ways of pedagogical interaction.

The development of pedagogical thinking becomes both a process and a result of teaching a future teacher. Based on this, as well as the significance of certain tasks in the formation and development of the pedagogical thinking of the future teacher, the system of pedagogical tasks was grouped by us as follows:

- information and analytical (tasks aimed at the formation of students' knowledge in the field of the strategy of pedagogical activity);

- $\quad$ analytical and synthetic (tasks related to the formation of knowledge and skills of students to highlight, analyze and explore the properties of the components of pedagogical systems);

- design and engineering (tasks related to the formation of students' skills to develop an individual project of the process of pedagogical activity);

- organizational and preparatory (tasks aimed at the formation of mental operations associated with the planning and organization of individual and collective educational activities);

- operational and practical (tasks aimed at forming value judgments, correcting the process and the result of pedagogical activity).

The basis of the teaching model, implemented in the conditions of the given approach, was formed by the principles: the student's subject activity, his controlled development as a future teacher-professional, the systemic orientation of the educational process towards the student's mastery of productive theoretical and practical thinking.

By the above, a model for the formation of a teacher-professional in the learning process was constructed, as well as a model for organizing the process of developing students' pedagogical thinking based on a task approach (Fig. 5).

\section{Analysis of results and discussion.}

The proposed teaching methodology was tested in the same universities and compared with the initial result (Fig. 1), i.e. "control group" - all students of 2-4 courses. The student's mastery of professional and pedagogical thinking was carried out in various forms of training. So, lecture forms of work provided the student, on the one hand, with the necessary system of theoretical knowledge, and on the other, with methods of theoretical reasoning. In this regard, several types of lectures were tested: informative; educational problem; problem-research.

The primary condition for the development of a student's theoretical thinking at a seminar was the possibility of his participation in discussion with an equally informed fellow student. Formation of 
readiness to participate in the debate was one of the specific tasks of the seminars and the technique of their conduct.

Practical exercises performed the following roles: development of students' practical skills; mastering the system of methods of experimental pedagogical research; inclusion of theoretical knowledge in solving practical professional problems.

Figure 5. The proposed model of formation of pedagogical thinking of future teachers

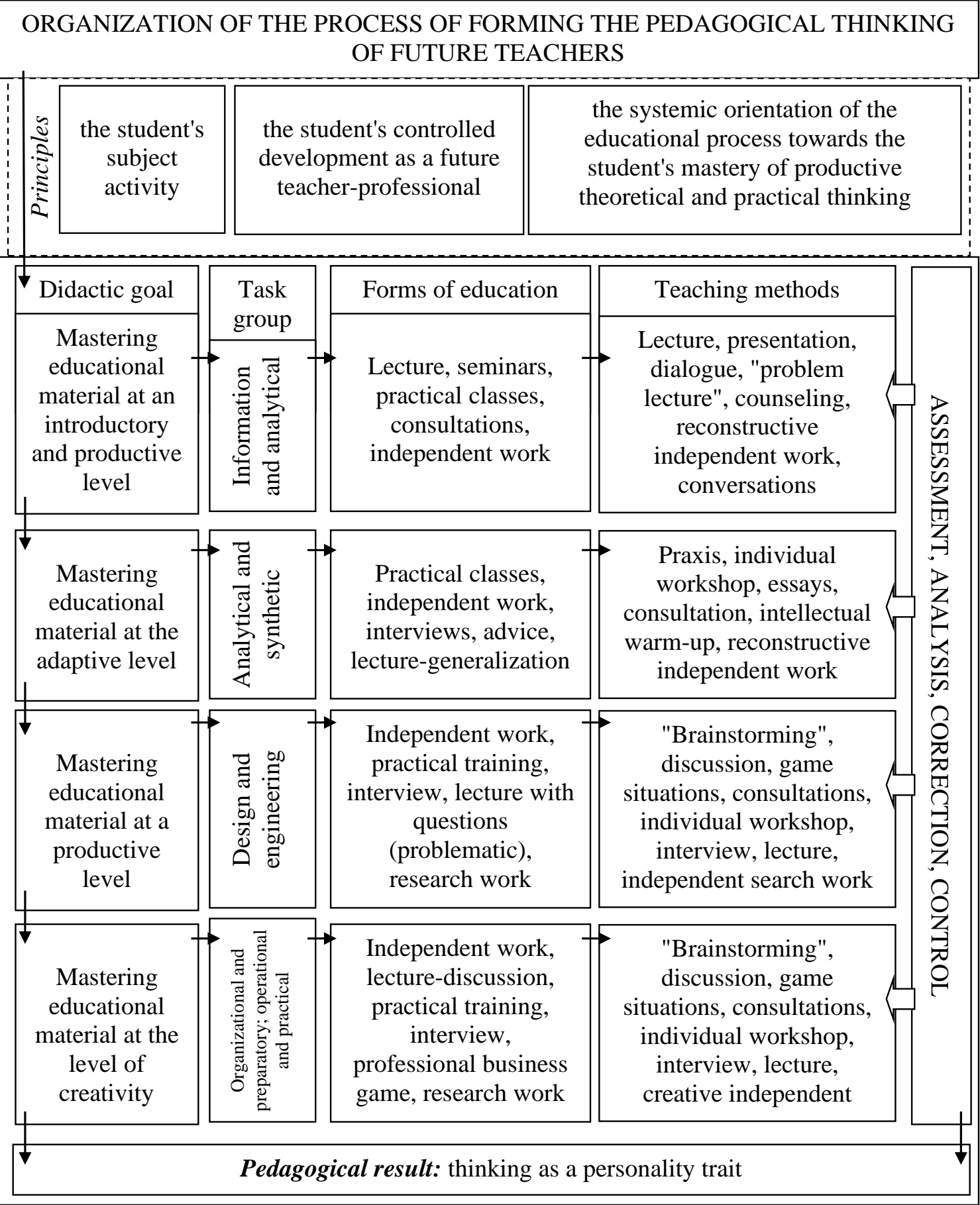

Source: Research findings

Analysis of the results obtained shows a significant increase in the criteria (Fig. 6).

It should be noted that, firstly, all indicators increased (on average, the total growth was $26 \%$ and $29 \%$, the maximum change of the indicator is $48 \%$, the minimum is $10 \%$ ), but those qualities that were developed to a greater extent showed a more significant growth; secondly, the experiment revealed several "side" positive aspects: improved student attendance and their involvement in the 
educational process, which was manifested in an increase in the number of students who came to consultations, an increase in the number of requests from students to study additional literature on the topic, to extra research work, etc., which may be possible future directions for study.

Figure 6. Results of observation of the development of pedagogical thinking in students after the implementation of the proposed model (2017-2019 years of study)

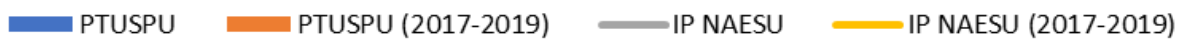

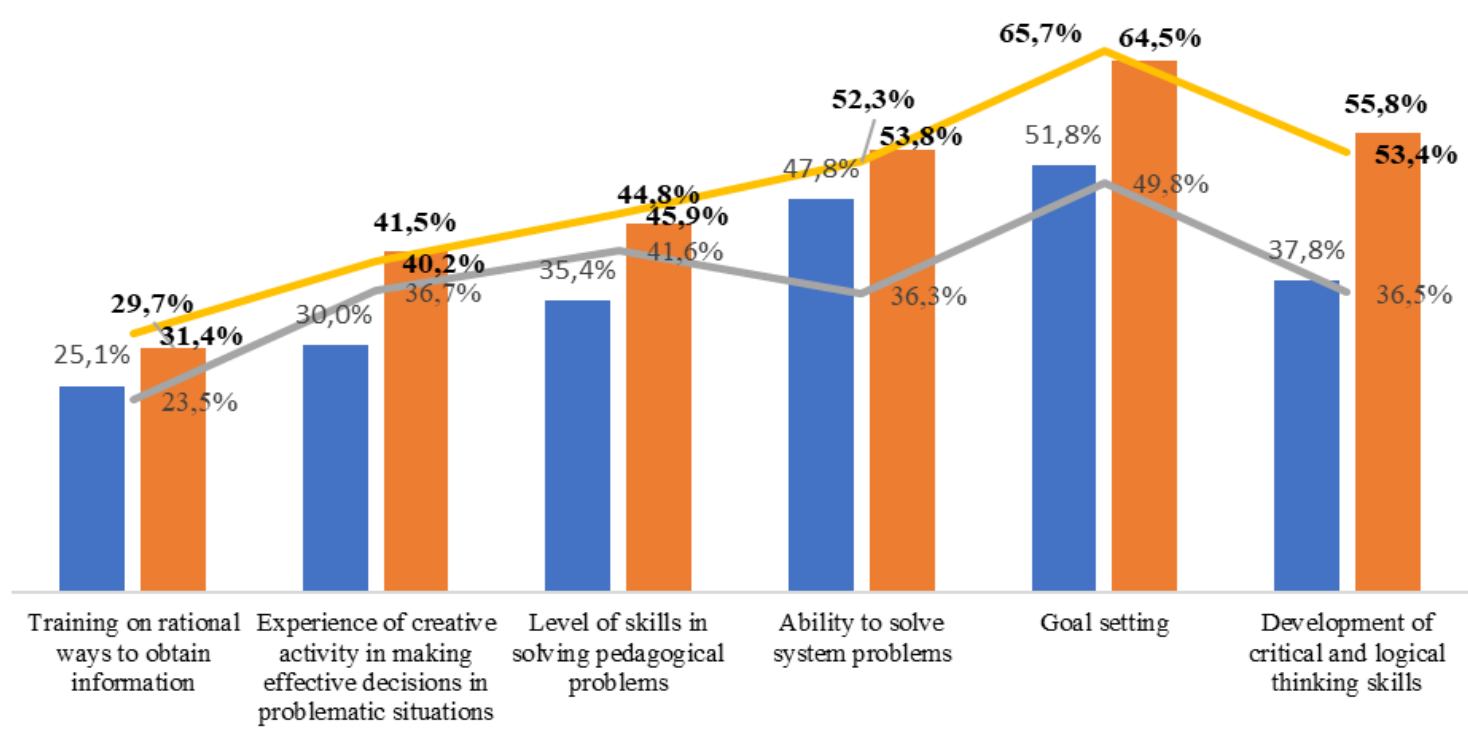

Source: Research findings

\section{Conclusions.}

The emphasis in modern education is transferred from the subject content to the operational skills of the individual to navigate in the information space, to find, process and apply the necessary information in their activities. The success of training depends on how effectively modern technologies and teaching aids are used, whether adequate access to information resources is created, and whether the conditions and terms of training allow mastering the necessary competencies. It is needed to combine modern requirements for future professionals (international cooperation, participation in research and professional projects, a sufficient level of practical training).

To increase the effectiveness of professional training of students is necessary to carry it out according to specially developed innovative programs, which should include a set of professionally oriented tasks with special game techniques, work with reference schemes-summaries, actively use pedagogical sketches and situations that reveal the specifics of teaching. A modular rating system should be used to improve the acquisition and verification of the level of knowledge.

An essential factor in the professional development of the future teacher is practical training. After all, it gives the opportunity to make sure of the correct choice of future profession, to see yourself in the role of a teacher, better to understand the psychological characteristics of primary school students. This is the novelty of future teacher training in higher education in the light of the requirements of the Bologna Process, which is so actively unfolding. Changes in pedagogical knowledge are designed to ensure high competitiveness of future graduates. His education must be fundamental, high-quality, and be carried out in an organic relationship with science and pedagogical practice. A graduate of a pedagogical university must be fluent in information technology, several foreign languages, and an additional (non-teaching) profession. 


\section{References}

1. Boichenko, V. (2015). Levels of Future Teachers' Pedagogical Thinking Formation: Results of Pedagogical Diagnostics. The Advanced Science Journal, 6, pp. 73-78. DOI: 10.15550/ASJ.2015.06.073

2. Colton, A., Sparks-Langer, G., Tripp-Opple, K. \& Simmons, J. (1989) Collaborative Inquiry into Developing Reflective Pedagogical Thinking. Action in Teacher Education, 11:3, pp. 44-52. DOI: 10.1080/01626620.1989.10462737

3. Demikhova, N.V., Smiianov, V.A., Prikhodko, O.A., Telizhenko, O.M., Lukyanikhin, V.O., Lukyanikhina, O.A., \& Demikhov, O.I. (2016). Information and telecommunication technologies and problem-based learning in the formation of competitive competence in medical masters of Sumy state university. Azerbaijan Medical Journal, 2, pp. 95-101.

4. Milner-Bolotin, M. (2020). Deliberate Pedagogical Thinking with Technology in STEM Teacher Education. In: Ben-David Kolikant Y., Martinovic D., Milner-Bolotin M. (eds) STEM Teachers and Teaching in the Digital Era. Springer, Cham., pp. 201-219. DOI: 10.1007/978-3-030-29396-3_11

5. Mylläri, J., Kynäslahti, H., Vesterinen, O., Vahtivuori-Hänninen, S., Lipponen, L., \& Tella, S. (2011). The students' pedagogical thinking and the use of ICTs in teaching. Scandinavian Journal of Educational Research, 55(5), pp. 537-550. DOI: 10.1080/00313831.2011.555920

6. O'brien M. (2012) Portraits of Pedagogical Thinking. In: Whisperings from the Corridors. SensePublishers, Rotterdam, pp. 35-51 DOI: 10.1007/978-94-6209-164-1_4

7. Prokopenko, O., Osadchenko, I., Braslavska, O., Malyshevska, I., Pichkur, M., \& Tyshchenko, V. (2020). Competence approach in future specialist skills development. International Journal of Management, 11(4), pp. 645-656.

8. Salminen, J., \& Annevirta, T. (2016). Curriculum and Teachers' Pedagogical Thinking When Planning for Teaching. European Journal of Curriculum Studies, 3 (1), pp. 387-406.

9. Suriya I. Gilmanshina, S. et al. (2015). Professional Thinking Formation Features of Prospective Natural Science Teachers Relying on the Competence-Based Approach. Review of European Studies, 7(3), pp. 341-349. DOI: 10.5539/res.v7n3p341

10.Tkachenko, V., Kuzior, A., \& Kwilinski, A. (2019). Introduction of Artificial Intelligence Tools into the Training Methods of Entrepreneurship Activities. Journal of Entrepreneurship Education, 22(6), 1-10. https://www.abacademies.org/articles/Introduction-of-artificial-intelligence-tools-15282651-22-6-477.pdf

11.Trigwell, K. \& Shale, S. (2004). Student learning and the scholarship of university teaching. Studies in Higher Education, 29(4), pp. 523-536.

12.Vozniak, V. (2019). New pedagogical thinking: the essential characteristics. Problems of Humanities Philosophy, 41, pp. DOI: 10.24919/2522-4727.41.168523 